\title{
VISIBLE LIGHT SOLAR PHOTOCATALYTIC DEGRADATION OF PULP AND PAPER WASTEWATER USING DYE-SENSITISED $\mathrm{TiO}_{2}$
}

\author{
S.Shanmuga Priya ${ }^{1}$, Aniruddha Deshpande ${ }^{2}$, Ruthu Dwarakanath ${ }^{3}$ \\ ${ }^{1}$ Associate Professor, Dept. of Chemical Engineering, MIT, Manipal University, Karnataka, India \\ ${ }^{2}$ Student, Dept. of Chemical Engineering, MIT, Manipal University, Karnataka, India \\ ${ }^{3}$ Student, Dept. of Chemical Engineering, MIT, Manipal University, Karnataka, India
}

\begin{abstract}
With the growing number of industries there are large volumes of wastewater generated every day. Pulp and paper mills are highly polluting as they release effluents containing organic pollutants, and high levels of Biological Oxygen Demand (BOD) and Chemical Oxygen Demand (COD). Even though well-established processes exist to treat these effluents, there are only a few processes which are energy efficient. Conventional treatment methods are not effective for the degradation of toxic organic pollutants, hence other treatment techniques are necessary. One of the recent developments in this field is the Advanced Oxidation Process (AOP). Solar photocatalysis is a type of AOP which utilises UV light to activate semiconductor photocatalyst in order to produce highly reactive radical species. $\mathrm{TiO}_{2}$ is a widely used catalyst for this purpose, to oxidise or reduce the organic pollutants in industrial wastewater. However, photocatalysis using visible light has been receiving increased attention hence, modification of $\mathrm{TiO}_{2}$ is necessary for its enhanced response to visible light. There are many methods for modifying TiO ${ }_{2}$, such as doping and photo-sensitisation. This study focusses on the modification of $\mathrm{TiO}_{2}$ using the method of dye-sensitisation (photo-sensitisation) with the dyes rhodamine B and methylene blue. Solar photocatalytic experiments were carried out for the degradation of pulp and paper wastewater, at different conditions like varying catalyst loading (500mg, 600mg, 750mg and 1000mg of catalyst for 300ml of aqueous wastewater) and effluent concentration $(20 \mathrm{ml}, 25 \mathrm{ml}, 30 \mathrm{ml}$ and $35 \mathrm{ml}$ of wastewater). Preliminary tests were done to determine the best conditions for photocatalytic degradation, and these were applied for final tests.
\end{abstract}

Keywords - Solar Photocatalysis, Visible Light, Dye Sensitisation, Pulp and paper, Methylene blue, Rhodamine B, $\mathrm{TiO}_{2}$ catalyst.

\section{INTRODUCTION}

Water is of great demand for household applications and industrial purposes. In India the demand for water is ever increasing in various sectors and it is projected that by 2020 , India will be a water-stressed nation. Industries are heavily dependent on water as it has a vital role in numerous processes, hence there is a need to undertake large scale, well monitored treatment processes not only for the safe disposal of wastewater, but also for reusing it. Indian paper mills utilise a wide variety of cellulosic and non-cellulosic raw materials, derived from forest wood, agro based and recycled paper. For various operations, pulp and paper mills require large volume of water and in turn release huge amount of effluent in the form of black liquor loaded with many pollutants. The black liquor effluent is dark brown in colour and associated with high biochemical oxygen demand (BOD), chemical oxygen demand (COD), total solids and total organic carbon (TOC). Treatment methods include chemical coagulation, flocculation, sedimentation, flotation, filtration and other biological methods like activated sludge process, trickling filters, stabilization pond, anaerobic digestion, lagooning and the like [1]. Recently solar treatment methods have also been incorporated for the treatment of pulp and paper mill effluents.
Solar energy is the most abundant resource and has the highest potential amongst all renewables. Hence, this renewable energy can be harnessed to solve the energy and water problems economically, efficiently and, in an ecofriendly manner. Since India is situated in the tropical region, most parts of the country experience clear, sunny weather for about 250-300 days per annum which makes India a suitable site for solar based treatment processes.

Advanced Oxidation Process (AOP) can effectively treat organic pollutants found in industrial effluents having high chemical stability and low biodegradability. AOPs are being considered as alternatives to conventional technologies because they degrade hazardous organic compounds rather than transferring them from one to another phase [2]. Complete mineralisation of organic pollutants to $\mathrm{CO}_{2}$ and halogenated compounds to halide ions maybe achieved by AOPs [3]. Solar photocatalysis is a type of AOP which mainly involves UV light, in the presence of a semiconducting photocatalyst to convert contaminants to simpler non-toxic compounds. This study focusses on the visible light solar photocatalysis as it constitutes a larger fraction of the solar spectrum, and due to this visible light has greater quantum efficiency in comparison to UV light [4]. 
Photoreactions do not occur on illumination with light alone. These reactions often require the use of a photocatalyst. In the case of semiconductor material the role of photons is to generate electron $\left(\mathrm{e}^{-}\right)$hole $(\mathrm{h}+)$ pairs that take part in subsequent redox reactions with the surface adsorbed molecules to yield the ultimate products. When light of a certain wavelength falls on a semiconductor and its energy is more than or equal to the band gap energy of the semiconductor, electrons would be excited from the valence band to the conduction band of the semiconductor and holes would be left in the valence band. These electrons and holes undergo subsequent oxidation and reduction reactions with any species, which are adsorbed on the surface of the semiconductor to give the necessary products [5].

$\mathrm{TiO}_{2}$ is the most widely used catalyst for photocatalytic experiments as it is non-toxic, inexpensive, stable and photoactive [6]. $\mathrm{TiO}_{2}$, as it is, can be excited only by UV light due to its large band gap energy of 3.2ev. However visible light does not possess enough energy to activate it as a photocatalyst, hence the physicochemical properties of $\mathrm{TiO}_{2}$ need to be modified suitably [5]. Dye sensitisation is a technique used to reduce its band gap energy requirements. Photosensitized degradation process, assisted by visible light, involves the initial excitation of the surface adsorbed dye followed by the charge injection to the conduction band of the semiconductor which results in the photocatalytic degradation reaction. Dye molecules adsorbed on the surface extend the range of excitation energies of the semiconductor into visible region. Fig 1 shows the chemical structure of the dye used for study. In the recent studies, the prospect of $\mathrm{TiO}_{2}$ surface adsorbed methylene blue and rhodamine $\mathrm{B}$ has been examined for the decomposition of various water bound organic pollutants in the presence of visible light and air (Debabrata Chatterjee et.al. 2002). Photo-excited methylene blue, accepts an electron to produce semimethylene blue dye species, whereas, surface adsorbed rhodamine $\mathrm{B}$ upon excitation injects electrons to the conduction band of the semiconductor [7].a

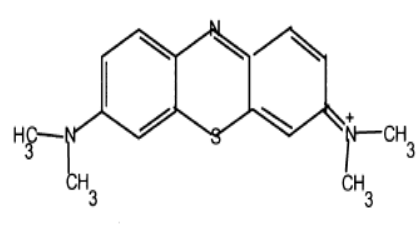

Methylene Blue

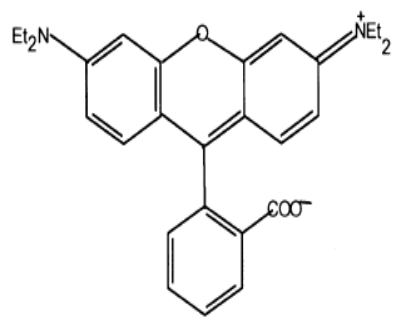

Rhodamine B
Fig 1: Chemical structure of the dyes used

Unlike solar thermal processes, which require large amounts of photons at any wavelength to reach a specific temperature range, solar photocatalytic processes require only the highenergy short-wavelength photons to promote photochemical reactions [8]. In photochemical processes

- The fluid must be directly exposed to solar radiation and therefore the absorber must be transparent to the photons.
- Temperature usually does not play a significant role, so no insulation is required.

The different types of solar collectors are -

- Concentrating type

$>$ Parabolic Trough concentrator

$>$ Compound parabolic concentrator

- Non-Concentrating type - Flat plate collector

Parabolic Trough Collector (PTC) is a concentrating type of collector and the design is based on the collector used for solar thermal application. PTCs are unsuitable for photocatalytic applications for several reasons: water is heated, radiation flux is too high, and most of the photons are not used efficiently and high cost.

Compound Parabolic Collector (CPC) is a type of low concentration collector. They combine both the characteristics and advantages of parabolic concentrators and static flat systems. CPCs are considered the best option for solar photocatalytic processes.

Flat Plate Collector is a type of non-concentrating collector which consists of a static system with no solar tracking mechanism. These devices are oriented towards the equator at a specific inclination, depending on the latitude of the site. Their main advantage is their simplicity and low manufacturing cost. Their support structure is easier and cheaper to install than the concentrating systems and the area required for their installation is smaller. Also, these collectors are more economical because there are no moving parts or tracking mechanisms. However their beam-sunlight collection maybe less energy efficient, given their fixed orientation to the incoming radiation. They are much better adapted to small scale operations and make use of diffused radiation.[9-10]

In this study, the evaluation of the photocatalytic activity of surface modified, dye-sensitised $\mathrm{TiO}_{2}$ is done to effectively reduce the TOC and COD of pulp and paper mill effluent. Experimental parameters taken into account are the catalyst loading and the initial concentration of the effluent.

\section{EXPERIMENTAL}

\subsection{Materials}

Pulp and paper effluent samples were obtained from Bindal Papers Limited. The samples were taken from taken after primary treatment, hence being free of suspended solids. Table 1 shows the characteristics of the obtained samples.

Table -1: Characteristics of the untreated wastewater samples

\begin{tabular}{|l|l|}
\hline pH & 5.17 \\
\hline TOC & $464.2 \mathrm{mg} / \mathrm{lt}$ \\
\hline COD & $1120 \mathrm{mg} / \mathrm{lt}$ \\
\hline
\end{tabular}


Titanium dioxide nanopowder $\left(\mathrm{TiO}_{2}\right.$, Degussa, Rutile-85\%: Anatase-15\%, 99+\% purity, 20nm) was purchased from Nanoshel LLC. This $\mathrm{TiO}_{2}$ powder was dye-sensitised using Methylene blue and Rhodamine B. Methylene blue was purchased from Himedia, Mumbai (Ref RM116-100G, minimum assay 99.0\%). Rhodamine B AR (M.S) was obtained from SD Fine Chemicals Ltd. (SDFCL), Mumbai.

\subsection{Instrumentation}

Total Organic Carbon (TOC) was determined using Shimadzu TOC-L CPN. Calibration of the TOC analyser was carried out using potassium hydrogen phthalate standards.

UV-Vis spectrophotometer (Shimadzu UV-1800) was used to determine the concentration of the adsorbed dye on the $\mathrm{TiO}_{2}$. Spectrophotometry was carried out at $553.0 \mathrm{~nm}$ wavelength.

Chemical Oxygen Demand (COD) was determined by digesting the samples for two hours in the COD digester (Spectralab COD digester 2015M).

\subsection{Analytical Procedures}

Stock solution of a mixture of the two dyes, rhodamine B and methylene blue, was prepared by taking $60 \mathrm{mg}$ and 40 $\mathrm{mg}$ respectively in 1 litre of distilled water. $40 \mathrm{ml}$ of the stock solution was taken and mixed with distilled water to obtain 1 litre of this aqueous dye with a concentration of $10^{-}$ ${ }^{5} \mathrm{M}$ and at $\mathrm{pH} \sim 5$. Dye sensitisation of $\mathrm{TiO}_{2}$ was done by taking $500 \mathrm{mg}$ of $\mathrm{TiO}_{2}$ in $50 \mathrm{ml}$ of aqueous solution of dye and magnetically stirring (at $160 \mathrm{rpm}$ ) it in the dark for 4 hours [7] [9]. The resulting mixture was subjected to vacuum filtration to obtain the dye adsorbed $\mathrm{TiO}_{2}$ and the supernatant liquid. The concentration of the adsorbed dye was determined spectrophotometrically by measuring the difference in absorbance of free dye and that of the supernatant liquid.

\subsection{Photocatalytic Experiments}

For this study a flat plate solar collector was fabricated using a wooden table inclined at an angle in accordance to the geographical location and borosilicate glass tubes were used as reactors. A mirror was placed for effective utilization of sunlight.

In a typical experiment $300 \mathrm{ml}$ of aqueous pulp and paper effluent was taken in the reactor, with a catalyst loading of $2000 \mathrm{mg} / \mathrm{lt}$ [7] [9]. $30 \mathrm{ml}$ of the prepared dye solution was also added to the reactor. The reactor was kept open to provide adequate oxygen and its contents were stirred at regular intervals. After chosen intervals samples of the reaction mixture were collected and TOC analysis was done. COD analysis was also done after the completion of the reaction. The remainder of the reaction mixture was filtered by vacuum filtration to recover the spent catalyst. The recovered $\mathrm{TiO}_{2}$ was also dye-sensitised for further experiments.

\section{RESULTS AND DISCUSSION}

The photocatalytic activity of the surface modified $\mathrm{TiO}_{2}$ was evaluated in preliminary tests to determine the most appropriate conditions to apply in the final tests and shown in Table 2.

Table -2: Results of preliminary test

\begin{tabular}{|l|l|l|l|l|}
\hline & I & II & III & IV \\
\hline $\begin{array}{l}\text { TOC-30min } \\
\text { (ppm) }\end{array}$ & 260.7 & 234.5 & 215.6 & 379.8 \\
\hline $\begin{array}{l}\text { TOC-3 hrs } \\
\text { (ppm) }\end{array}$ & 218 & 193.8 & 212.5 & 332.2 \\
\hline $\begin{array}{l}\text { COD-3 hrs } \\
\text { (ppm) }\end{array}$ & 426.67 & 117.33 & 240 & 1066.67 \\
\hline
\end{tabular}

\section{Legend}

I - Effluent without dye and dye adsorbed $\mathrm{TiO}_{2}$

II - Effluent with dye and dye adsorbed $\mathrm{TiO}_{2}$

III - Effluent with dye and dye adsorbed $\mathrm{TiO}_{2}$ (recycled)

$\mathrm{IV}$ - Effluent without dye or dye adsorbed $\mathrm{TiO}_{2}$

Inferring from the preliminary tests, the best suited condition for photocatalytic degradation was found to be the one which contained dye as well as dye adsorbed $\mathrm{TiO}_{2}$, hence it was applied to the final tests. Evaluation of the photocatalytic activity of the photocatalyst is highly dependent on a number of parameters. The parameters that were taken under consideration in this study were initial effluent concentration and catalyst loading.

\subsection{Catalyst Loading}

Chart -1 illustrates the influence of catalyst concentration on the degradation of the organic pollutants present in the wastewater. Experiments were performed at 4 different concentrations i.e. $500 \mathrm{mg}, 600 \mathrm{mg}, 750 \mathrm{mg}$ and $1000 \mathrm{mg}$ for $300 \mathrm{ml}$ of aqueous wastewater. It can be seen that the degradation rate is the highest in the first 20 minutes and it follows a linear relationship. Chart -2 shows that the maximum degradation is achieved at $\sim 750 \mathrm{mg}$ (catalyst loading - 2500mg/lt). In order to avoid excess catalyst usage and to ensure total absorption of photons, optimum catalyst loading must be determined. Table 3 gives us the COD values after completion of the experiment. 


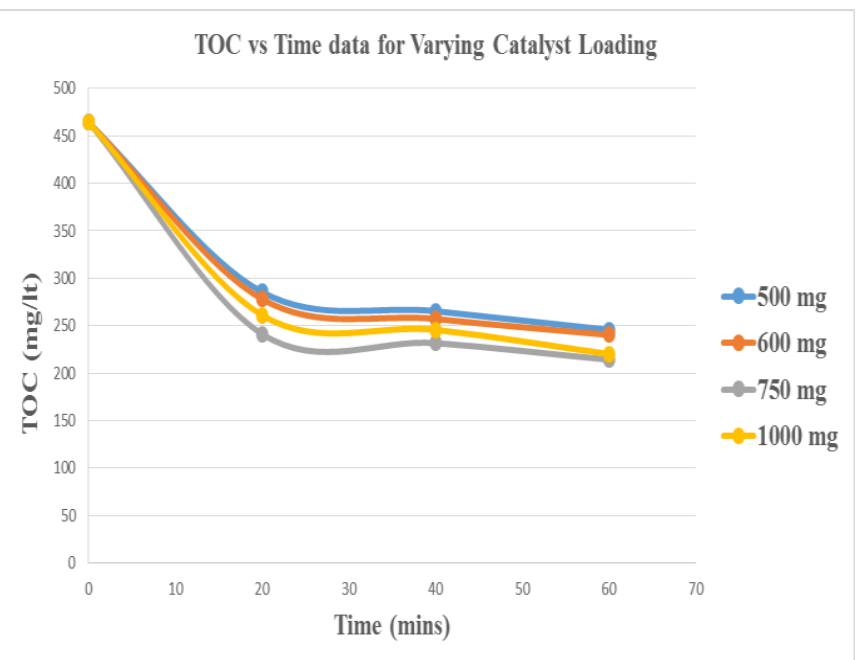

Chart -1: Reduction in TOC for varying catalyst loading.

Table -3: COD results after completion of reaction for varying catalyst loading.

\begin{tabular}{|l|l|}
\hline Catalyst Loading $(\mathbf{m g})$ & COD after $\mathbf{1 ~ h r}(\mathbf{m g} / \mathbf{l t})$ \\
\hline 500 & 426.66 \\
\hline 600 & 639.99 \\
\hline 750 & 373.33 \\
\hline 1000 & 586.66 \\
\hline
\end{tabular}

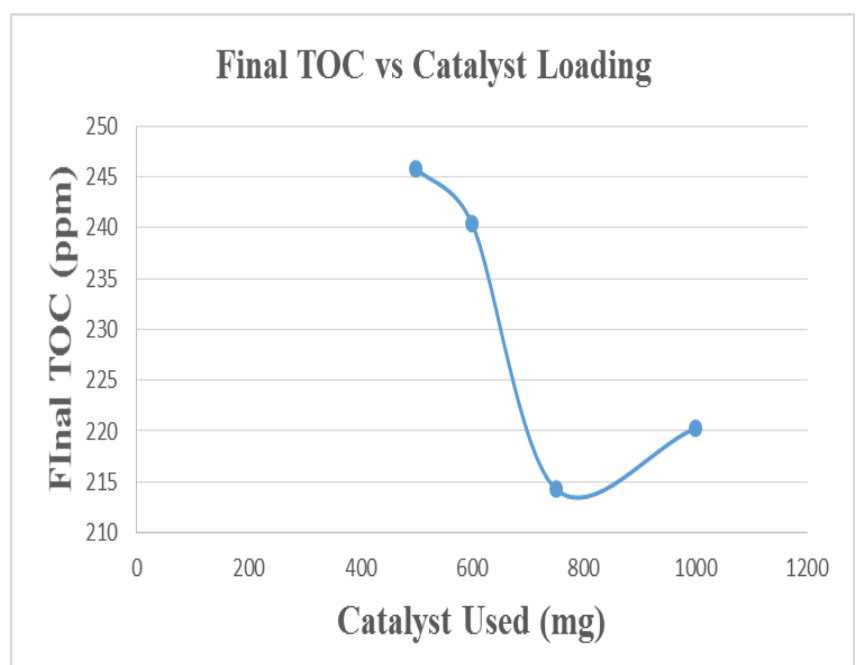

Chart -2: Graph showing the final TOC value as a function of catalyst used.

\subsection{Initial Effluent Concentration}

Chart -3 shows the degradation profile of the organic pollutants in the wastewater at different initial concentration of the effluent. Experiments were done using $300 \mathrm{ml}$ of aqueous solution of the wastewater at different initial concentrations i.e. $20 \mathrm{ml}, 25 \mathrm{ml}, 30 \mathrm{ml}$ and $35 \mathrm{ml}$ of effluent. In the first 20 minutes, the degradation rate of the organic pollutants is the same for all initial concentrations of the effluent, hence it does not play a significant role in the rate of degradation. COD was determined after completion of the experiment, as shown in table 4.

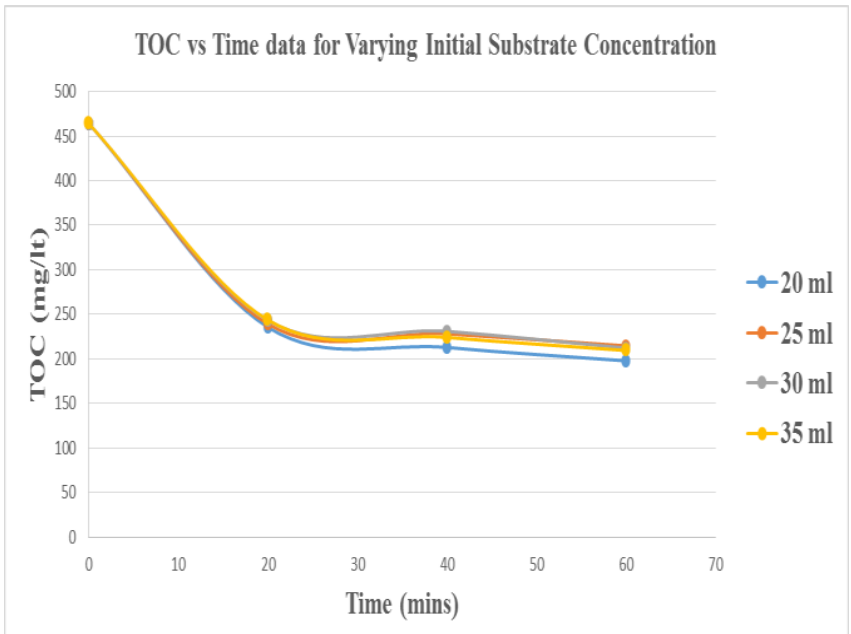

Chart -3: Reduction in TOC for varying initial substrate concentration.

Table -4: COD results after completion of reaction for varying initial substrate concentration.

\begin{tabular}{|l|l|}
\hline $\begin{array}{l}\text { Initial Substrate } \\
\text { Concentration }(\mathbf{m l})\end{array}$ & COD after 1 hr (mg/lt) \\
\hline 20 & 660 \\
\hline 25 & 576 \\
\hline 30 & 640 \\
\hline 35 & 514.28 \\
\hline
\end{tabular}

\section{CONCLUSION}

From the studies conducted it can be inferred that in the presence of visible light, the surface adsorbed methylene blue and rhodamine $\mathrm{B}$ can sensitise $\mathrm{TiO}_{2}$ semiconductor for the generation of oxidising and highly reactive radical species which decompose organic pollutants. Amongst the conditions considered for the experiments conducted, 750 $\mathrm{mg}$ of dye adsorbed $\mathrm{TiO}_{2}$ (catalyst loading $-2500 \mathrm{mg} / \mathrm{lt}$ ) showed the maximum reduction in TOC and COD.

$\mathrm{TiO}_{2}$ based photocatalysis is an effective treatment technique for wastewater although evaluation of photocatalytic performance is a complicated process which is influenced by many different parameters. These parameters include light intensity, presence of oxygen, catalyst loading, initial concentration of substrate, adsorption and $\mathrm{pH}$. Reproducible evaluation of results requires a careful selection of all parameters.

\section{ACKNOWLEDGEMENTS}

We are grateful to the Department of Chemical Engineering, MIT, Manipal, for providing us all the facilities to carry out the work for this project.

\section{REFERENCES}

[1] Narsi R. Bishnoi, R.K. Khumukcham, Rajender Kumar, "Biodegradation of pulp and paper mill effluent using anaerobic followed by aerobic digestion", Journal of Environmental Biology, 27(2) (2006) 405-408 
[2] Julián Blanco-Galvez, Pilar Fernández-Ibáñez, Sixto Malato-Rodríguez, "Solar Photocatalytic Detoxification and Disinfection of Water: Recent Overview", Solar Energy Division of ASME for publication in the Journal Of Solar Energy Engineering (2007) 4-15.

[3] R. Bauer, G. Waldner, H. Fallmann, S. Hager, M. Klare, T. Krutzler, S. Malato, P. Maletzky, "The photo-fenton reaction and the $\mathrm{TiO} 2 / \mathrm{UV}$ process for waste water treatment - novel developments", Catalysis Today 53 (1999) 131-144.

[4] Yanlong Tian, Binbin Chang, Jie Fu, Fengna Xi, Xiaoping Dong, "Yellow-colored mesoporous pure titania and its high stability in visible light photocatalysis", Powder Technology 245 (2013) 227-232.

[5] Debabrata Chatterjee, Shimanti Dasgupta, "Visible light induced photocatalytic degradation of organic pollutants", Journal of Photochemistry and Photobiology C: Photochemistry Reviews 6 (2005) 186-205.

[6] Brijesh Pare, David Swami, Prakash More, Tehmina Qureshi, T. R. Thapak, "Mineralization of Methylene Violet Dye Using Titanium Dioxide in Presence of Visible Light", Int. J. Chem. Sci.: 9(4), 2011, 16851697 ISSN 0972-768X

[7] Debabrata Chatterjee, Anima Mahata, "Visible light induced photodegradation of organic pollutants on dye adsorbed $\mathrm{TiO}_{2}$ surface", Journal of Photochemistry and Photobiology A: Chemistry 153 (2002) 199-204.

[8] Julian Blanco Galvez, Sixto Malato Rodriguez, "Solar Detoxification", United Nations Educational, Scientific and Cultural Organization (2003).

[9] Debabrata Chatterjee, Anima Mahata, "Demineralisation of organic pollutants on the dye modified $\mathrm{TiO}_{2}$ semiconductor particulate system using visible light", Applied Catalysis B: Environmental, 33 (2001) 119-125.

[10] T.Fotiou, T.M.Triantis, T.Kaloudis, A.Hiskia, "Evaluation of the photocatalytic activity of $\mathrm{TiO}_{2}$ based catalyst for the degradation and mineralisation of cyanobacterial toxins and water off-odour compounds under UV-A, solar and visible light", Chemical Engineering Journal 261 (2015) 17-26.

\section{BIOGRAPHIES}

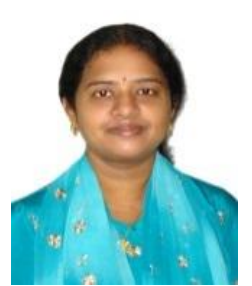

Dr.S.Shanmuga Priya is working as an Associate Professor in the Department of Chemical Engineering, Manipal Institute of Technology, Manipal University, Karnataka, India. She has 4 years of research experience and 6 years of teaching experience. She has 20 journals, 40 conferences, 1 book and 3 book chapters to her credit in international and national publications.

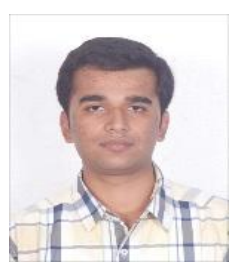

Aniruddha Deshpande was born in 1993 in Saharanpur, India. He is currently pursuing his Bachelor's Degree in Chemical Engineering from MIT, Manipal. $\mathrm{He}$ is in the final year and currently engaged in a project involving photodegradation of organic pollutants in industrial wastewater.

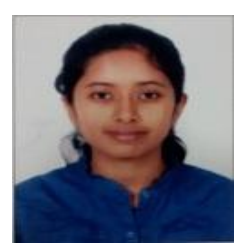

photodegradation wastewater.
Ruthu Dwarakanath was born in 1993 in Bangalore, India. She is currently pursuing her Bachelor's Degree in Chemical Engineering from MIT, Manipal. She is in the final year and currently engaged in a project involving of organic pollutants in industrial 